\title{
Quid Pro Quo Nature of Leadership Trust Formation - A Monadic Study from the Subordinate's Perspective
}

\author{
S. Sathya Narayanan ${ }^{1}$ \\ ${ }^{1}$ Faculty of Business Management, Majan College, Muscat, Sultanate of Oman \\ Correspondence: S. Sathya Narayanan, Faculty of Business Management, Majan College, P.O. Box: 710, PC 112, \\ Muscat, Sultanate of Oman. Tel: 968-9735-9509. E-mail: promisenarayanan@yahoo.co.uk
}

Received: September 5, 2012

doi:10.5539/ijbm.v7n21p113
Accepted: September 25, 2012 Online Published: October 23, 2012

URL: http://dx.doi.org/10.5539/ijbm.v7n21p113

\begin{abstract}
This study investigates the relevance of leader characteristics in influencing the leadership trust formation among subordinates through a structural model. Although previous studies on leadership trust have identified such antecedents, specific structural models of leadership trust formation are not established hitherto. Hypothesised relationships in this study are investigated using structural equation modeling to establish direct and indirect linkages between leader characteristics and leadership trust formation, thereby leading to an established model. The findings reveal that the tenure of the work relationship between a leader and subordinate and the leader's trustworthy behaviour will not directly influence leadership trust. The perceived ability of the leader and the interdependent nature of work directly influences trust formation in leaders. The trust reciprocity variable - the belief that the leader trusts the subordinate - significantly influences leadership trust. This research is cross-sectional in nature and three selected variables are measured through single item global scales, which call for further studies overcoming their inherent weaknesses. As this study is monadic from the perspective of the subordinates, a dyadic study including the leader's perspective is recommended. To generate leadership trust, a leader should not only exhibit trustworthy actions and behaviour but also should ensure that the subordinates believe that he/she trusts them. Therefore, a leader's trustworthy actions will create a reciprocal belief among subordinates and in turn generate trust in leaders. The "give and take" nature of leadership trust formation is established through a structural model which is the unique contribution of this study to the extant literature.
\end{abstract}

Keywords: leadership, trust reciprocity, trust, leadership trustworthy behaviour, leadership trust

\section{Introduction}

Can leaders influence and have an impact on the trust levels of their subordinates? This is a challenging question which was addressed by many earlier researchers through their studies (Lewicki, McAllister, \& Bies, 1998; Kramer \& Tyler, 1996; Mayer, Davis \& Schoorman, 1995). Bromily and Cummings (1992) define trust as the expectation that the other individual will act in good faith towards fulfilling the commitments in an honest manner and without taking too much advantage of the trustor. The loss of trust in transactions between leaders and subordinates will lead to poor communication, lack of respect, backbiting, avoidance, inappropriate independence, spiteful conformity and deflection between them. This will be highly detrimental to the organisations (Goldsmith, 1991; Josephson, 1993; 1994; Walker \& Williams, 1995). In this context, this study aims to identify the antecedents to subordinates' trust in the leader and to establish a causal relationship among them using structural equation modeling. The findings of the study will help the leaders to display positive characteristics so as to enhance the trust level of their subordinates.

\section{Literature Review}

Amongst the various trust variables as identified in previous studies (Marquis, 2002; Mayer et al., 1995, Butler, 1991; Gabarro, 1978; Kee \& Knox, 1970) the leader behaviour and trustworthiness carried importance in the recent literature (Korsgaard, Brodt \& Whitener, 2002; Whitener, Brodt, Korsgaard \& Werner., 1998). Much of the recent research has studied the role of trust antecedents or the trustor characteristics that led to the formation of trust (Kramer, 1999; Mayer et al., 1995; Whitener et al., 1998). Marquis (2002) contends that the application of quantitative analysis in the study on antecedents of trust is limited and further opines that the immediate manager's behaviour and its impact on subordinate's trust should be analysed. 
Stability of managerial personnel was found to have a strong impact on the trust level of the subordinates. Longer tenure in the working relationship between the manager and subordinates helps in building trust (Marquis, 2002; Kramer, 1999; Whitener et al., 1998). On the other hand, contrasting findings emerged stating the lack of relationship between the tenure of the leader with subordinates and their corresponding trust levels (Dirks \& Ferrin, 2002; Cardona \& Elola, 2003; Kiluchinov, 2011). Though mutually conflicting outcomes are evident, the relevance of the tenure of the leader and subordinates in trust formation requires a consideration for a conclusive outcome and therefore included in this study:

H1: The tenure of work relationship between the leader and subordinates significantly influences the amount of trust the subordinates have towards their leaders.

Recent studies on leadership trust emphasize the relevance of leader behaviour and characteristics in influencing the trust formation in followers. Mayer and Davis (1999) maintain that calculated efforts and specific actions from a leader will lead to trust formation. Subordinates trust their leader when they are trustworthy (Hosmer, 1995; Mayer et al., 1995). Das and Teng (2004) argue that the subordinate's trust is a function of the behaviour of the leader who wants to be trusted. Webber (2002) proposes that the actions and behaviour of a leader are important in creating trust. Kramer and Tyler (1996) opine that the expectations of the subordinates towards their leader should be consistent to generate leader trustworthiness and such trustworthiness is based on a history of interactions they have with their leader. Therefore, it is essential for the leaders to be consistent in their behaviour, as trust is history based. In this study, the leader characteristics and behaviour are considered as relevant and important factors in determining the trust formation:

H2: The leader characteristics and behaviour will have a significant impact on the trust formation in subordinates.

The leader characteristics and behaviour are broader in scope. To narrow down this hypothesis, specific variables of leader characteristics and behaviour are identified for this study. The perceived ability of the leader carried significance in previous studies. Mayer et al., (1995) define the ability of the leader as the skills, competencies and characteristics that enable them to influence their subordinates. Competence and ability of leaders in terms of interpersonal skills, technical skills, and expertise as an antecedent to trust in leaders is discussed in earlier studies (Gabarro, 1987; Mishra, 1996; Mullen, 1998). Cardona and Elola (2003) established the role of perceived ability in leadership trust formation.

H2a: The perceived ability of the leader will have a significant impact on the leadership trust formation.

The extent of interdependence of the task between the leaders and subordinates can affect the trust formation in leaders. Mayer et al., (1995) argue that leaders and subordinates depend on each other in various ways to achieve personal and organisational goals. Therefore, the extent of interdependence of jobs has an influence on the trust levels between the leaders and subordinates. On the contrary, Cardona and Elola (2003) found that task interdependence has no relation to leadership trust. As task interdependence and leadership behaviour are closely related they are also included in this study.

$H 2 b$ : The task interdependence between the leader and subordinates will have a significant impact on the leadership trust formation.

Mayer et al., (1995) identified that the trustworthiness of leaders is widely based on their ability, benevolence and integrity. Here, benevolence is the extent the trustor believes the trustee is intending to do good acts and show concern. This emphasizes the role of concern shown by the leaders in creating their trustworthiness. The trustee's behaviour can influence the trustor's judgment of trustworthiness (whitener et al., 1998). Further, Mayer et al., (1995) define integrity as the perception by subordinates that the leader follows a set of acceptable principles. Robinson (1996) emphasizes that apart from benevolence, integrity and behavioural consistency of leaders, their open communication and sharing of control with subordinates influences their trustworthiness. Managerial trustworthy behaviour is considered to be an important antecedent of trust between leader and subordinate relationships (Cardona \& Elola, 2003).

$H 2 c$ : The trustworthy behaviour of the leader will have a significant impact on the leadership trust formation.

Trust Reciprocity: Subordinates can trust their leader when they feel confident that their obligations are met through their leader. The leader's personal qualities and favourable behaviour towards subordinates' welfare is found to increase the trust levels of them towards their leader. Therefore, subordinates' trust in leaders is considered to be reciprocal and often dependent upon the trustworthy actions of leaders (Gouldner, 1960).

Kramer et al. (1996) argues that lower level employees over-personalise the task-oriented trust based cues from their leader, leading to reciprocal disappointments. He advocates that leaders have to manage the governance 
context of the subordinates to reduce misunderstandings between them. This gives proper grounding to hypothesise that the subordinate's belief that the leader's actions are favourable towards them will generate reciprocal trust towards their leader. Cardona and Elola (2003) lend their support to this through their finding that trust reciprocity is positively related to leadership trust. This relationship is hypothesised as follows.

H3: The trust reciprocity variable -'belief that the leader trusts the subordinate'- will significantly influence the leadership trust formation.

\subsection{Conceptual Framework}

To establish the proposed hypotheses, a structural model is conceptualized. It forms the basis for the initial hypothesised model in SEM analysis. The demographic variable - tenure with the leader - is treated as the primary variable in the model. The leader characteristics, which include perceived ability of the leader, perceived task interdependence and leader trustworthy behaviour, are treated as secondary independent variables. The trust reciprocity variable is treated as the tertiary independent variable. It is unique in its hypothesis that, the tertiary variable "belief that leader trusts subordinates" is considered as an intermediary variable between the other leader characteristics and the dependent variable "trust in leaders".

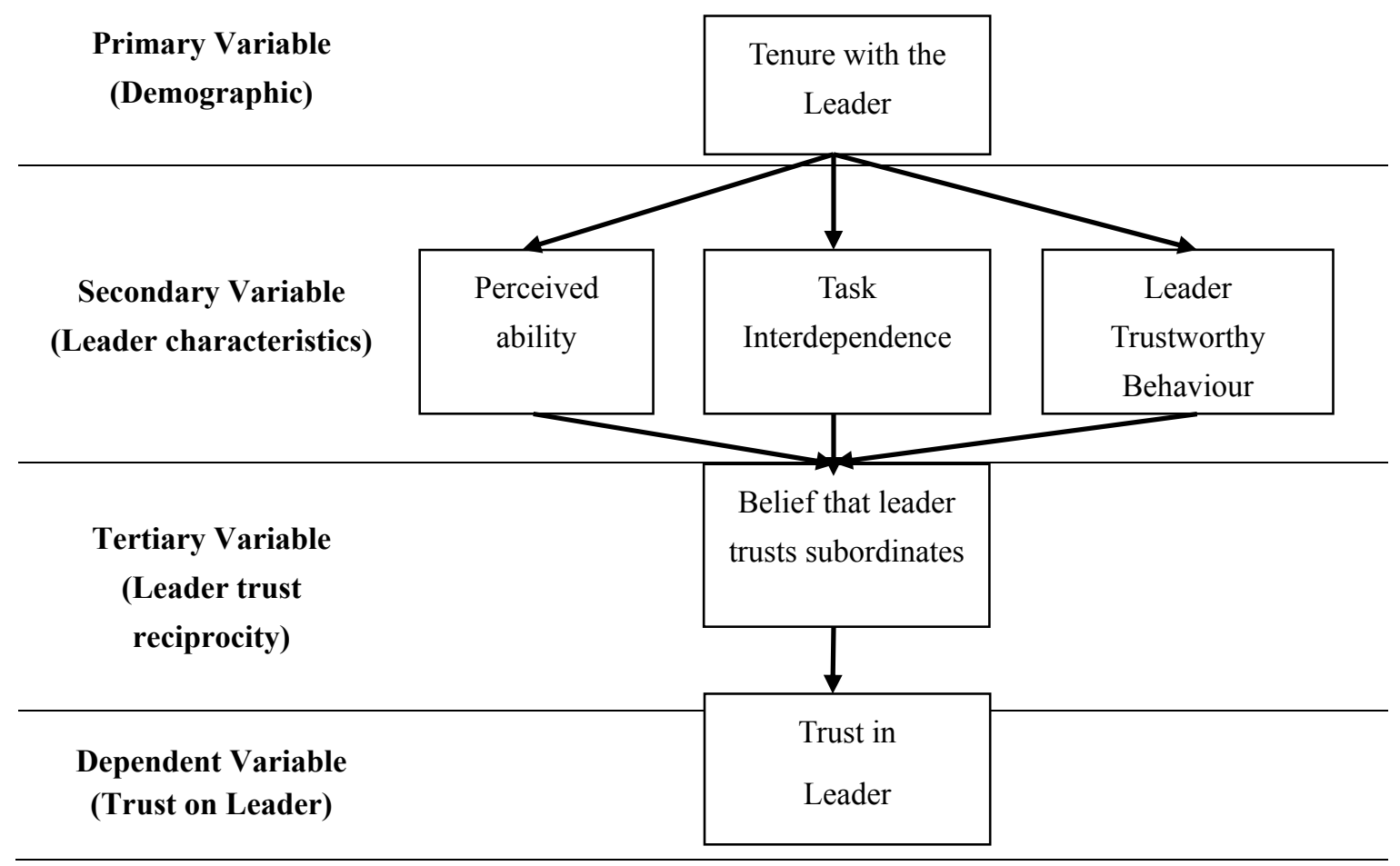

Figure 1. Conceptual framework

This lays the foundation for the quid pro quo nature of leadership trust formation. I.e. The subordinates will trust their leaders only when they believe that the leader trusts them (refer figure 1). Moreover, this framework identifies the various antecedents to trust in leaders and helps to establish the causality of them in leadership trust formation. Marquis (2002) used similar variables in her study based on the adaptation of the model as proposed by Mayer (1995). Cardona and Elola (2003) also used similar variables in their study and their relationship was established using hierarchical regression model. All these studies lacked evidence for directionality and causality, which paved the way for this proposed structural model.

\section{Methodology}

\subsection{Measurement Design}

The variables identified in the conceptual framework are measured using multiple items in a questionnaire. The Leader Trustworthy Behaviour (LTB) is measured through a scale developed by Whitener et al. (1998) which encompasses five categories, namely behavioural consistency, sharing and delegation of control, openness of communication, acting with integrity and demonstration of concern. This scale was further developed by Cardona and Elola (2003) following a theory-based deductive approach (Hinkin, 1995). The scale consists of 
fifteen items, with each category of LTB measured by three items. Following Butler (1991), one negative response question was added to each of the categories to avoid socially responsive bias. This also reduced the tendency to give acquiescent sets of responses (Cardona \& Elola, 2003). The LTB is measured by parceling all the fifteen items to form a single measure. This reduces the complexity of the model with fewer parameters to estimate. This process of partial aggregation can provide a meaningful fit for a complex model with a reasonable sample size (Heidt and Scott, 2007). Cardona and Elola (2003) reported an overall internal consistency alpha value of 0.88, which is an acceptable measure of reliability for any new instrument (Hair et al., 1998). The same instrument is used in this study and it is further validated using confirmatory factor analysis. The overall reliability score of the 15 -item scale from this study is 0.857 , which is acceptable and good (Kline, 1999).

The trust is measured using a single direct question "I trust my leader" in a five-point Likert scale ranging from strongly disagree to strongly agree. This approach is followed by Cardona and Elola (2003) in their study on trust and also by several others (Brockner, Siegel, Daly, Tyler, \& Martin, 1997; Robinson, 1996). Similarly, the "subordinate's perception of the superior's trust in them" is measured through a single direct item "I believe that my supervisor trusts me". The task interdependence between the subordinates and leader is measured through a single item scale as followed by Cardona and Elola (2003). These single-item scales are referred to as "Global scales" or clinical combinations where respondents will cognitively give a single combined global judgement (Ironson, Smith, Brannick, Gibson, \& Paul, 1989) on the measures. De Vellis (1991) argue that multiple-item scales assess the constructs in a better way than a single-item scale. Rossiter (2008) strongly argues that as long as the content validity of the item in a single item scale is established, no other validities are required.

The perceived ability of the leaders is measured through the opinion from the subordinates using a three-item scale which is adapted by Cardona and Elola (2003) from Schoorman, Mayer and Davis's (1996) six-item scale. The three-item perceived ability scale has a reported Cronbach's alpha value of 0.79 (Cardona \& Elola, 2003). The three items in the perceived ability scale are used as such in the model, without parceling them. In this study, the alpha value of the perceived ability scale is 0.585 which is lesser than the prescribed minimum of 0.70 , indicating weak reliability. This is attributed to the use of fewer items to measure the construct (Field, 2005). Kline (1999) opines that the complexity and diversity in measurement of psychological constructs sometimes realistically invite Cronbach's alpha values lesser than 0.7 .

\subsection{Sampling Design}

The external validity of the study is ascertained through a proper multi-stage sampling plan. In the first stage of sample selection, purposive sampling is used to select three organisations from a basket of manufacturing and service organisations in South India, based on the accessibility to the samples. Two service organisations (a placement consultancy firm and an outsourcing service provider) and one manufacturing organisation (edible oil manufacturing plant) are taken as the sampling base. In the second stage a census study is followed in each organisation. The sample size is determined through the basis of Tabachnick and Fidell's (2001) recommendation that at least 10 samples are required for every parameter to be estimated to ensure a model fit. Marquis (2002) recommends inclusion of more female respondents both in the lower level and middle level management positions, as the earlier studies mostly involved male employees. The service organisations have more female employees at the middle and lower levels of management. A total of 420 questionnaires are distributed in all the three organisations and the response rate in the Outsourcing organisation is $80.21 \%$ with 150 filled-in responses. The response rate in the manufacturing organisation is $71.67 \%$ with 86 filled-in responses and the placement consultancy organisation is $75.22 \%$ with 85 filled-in responses. A total of 321 completely filled-in questionnaires are gathered excluding the incomplete responses.

\subsection{Validity and Reliability of the Leader Trustworthy Behaviour Scale}

The construct validity of the Leader Trustworthy Behaviour instrument is established through a second order confirmatory factor analysis using Amos 6.0. The five factors as proposed by Whitener et al. (1998) are tested for construct validity using a second order factor analysis. The 15 items in the leader trustworthy behaviour scale are fitted with five first order factors, namely: behavioural consistency, sharing and delegation of control, openness of communication, acting with integrity and demonstration of concern. The higher order factor Leader Trustworthy Behaviour (LTB) is considered to have direct causal effects over the lower order factors (Kline, 2005). This hierarchical factor analysis facilitates parceling all the 15 items into a single LTB score. The overall Cronbach's alpha reliability measure for all the 15 variables is 0.857 , which is more than the prescribed minimum of 0.7 (Hair, Anderson, Tatham \& Black, 1998). This is equivalent to the reported internal consistency value of 0.88 by Cardona and Elola (2003). The second order confirmatory factor analysis, with a maximum likelihood solution, shows a good model fit with a chi-square value of 72.173, RMSEA value of .024 and C. 
$\mathrm{min} / \mathrm{df}$ value of 1.183. The other model fit measures like GFI, AGFI, TLI, CFI and NFI, are above 0.9, confirming the model fit.

\section{Analysis}

As the hypothesis involves verifying the role of multiple independent variables and their impact on the trust in leaders, the dependent variable, SEM analysis is preferred over the multiple regression analysis. SEM analysis reveals the causal relationships and the direct and indirect effects of the variables (Hair et al., 1998).

Table 1. Means, standard deviations, correlations and coefficient alphas

\begin{tabular}{lcccccccc}
\hline \multicolumn{1}{c}{ Variable } & Mean & SD & 1 & 2 & 3 & 4 & 5 & 6 \\
\hline 1. Tenure with the Leader & 24.21 & 34.79 & (NA) & & & & & \\
2. Trust in Leader & 4.08 & 0.99 & $.133^{*}$ & (NA) & & & & \\
3. Belief that Leader trusts them & 3.98 & 0.95 & $.226^{*}$ & $.667^{* *}$ & (NA) & & & \\
4. Perceived Interdependence & 4.15 & 0.88 & $.115^{* *}$ & $.418^{* *}$ & $.335^{* *}$ & (NA) & & \\
5. Leader Trustworthy Behavior & 3.612 & 0.59 & .069 & $.521^{* *}$ & $.536^{* *}$ & $.252^{* *}$ & $(.857)$ & \\
6. Perceived Ability of Leader & 3.681 & 0.86 & $.237^{* *}$ & $.472^{* *}$ & $.438^{* *}$ & $.314^{* *}$ & $.559^{* *}$ & $(.585)$ \\
\hline
\end{tabular}

Note: $\mathrm{n}=321$. Coefficient alphas are shown in parentheses along the diagonal.

$\mathrm{NA}=$ Single item scales. ${ }^{*} \mathrm{p}<.05 * * \mathrm{p}<.01$, two tailed test.

The initial hypothesised model is constructed based on the conceptual framework which includes the demographic variable "tenure with the leader", which is considered to be the primary variable. The secondary independent variables are the leader characteristics namely: "perceived ability", "task interdependence" and "Leader Trustworthy Behaviour". The tertiary variable is the trust reciprocity variable "belief that the leader trusts the subordinate". The hypothesised structural model is depicted in Figure 2. A mixture of fit indices including $\chi^{2}$, GFI, AGFI, RMSEA, TLI, CFI, NFI and C min./df are used to evaluate the hypothesised structural model. 


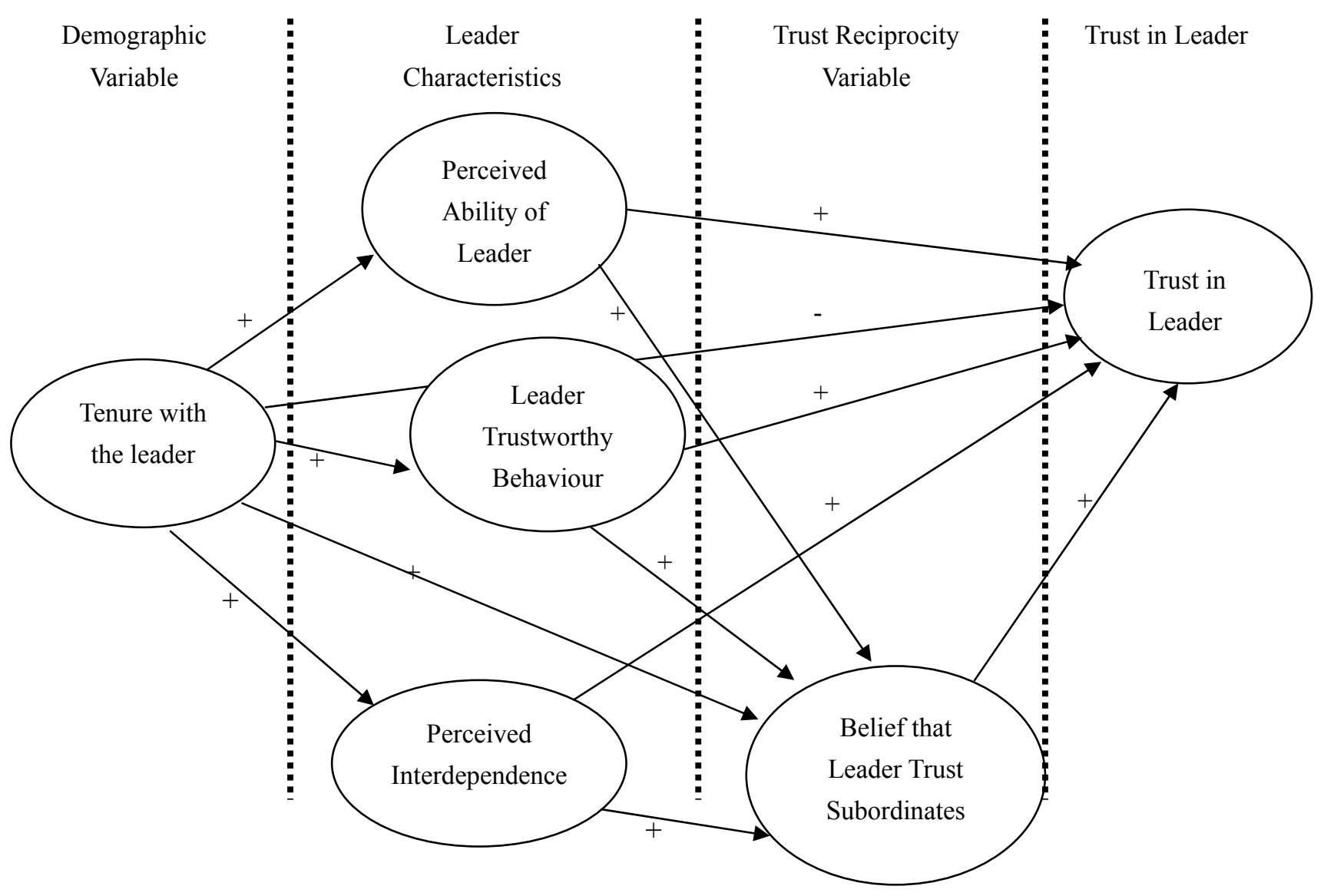

Figure 2. Initial hypothesized model

\subsection{Evaluating the Hypothesised Structural Model}

The hypothesised model is not supported and has a poor model fit, which is demonstrated by the fit indices as displayed in the table 2. The p value is less than .01 with all other goodness-of-fit indices less than 0.9 and RMSEA greater than .05, indicating poor structural fit (Hair et al, 1998; Kline, 2005). Similarly as identified from the table 3, all the hypothesised relationships in the structural model are supported except the relationship between the primary variable "tenure with the leader" and the dependent variables "trust in the leader" and "Leader Trustworthy Behaviour".

\subsection{Structural Model Re-Specification}

As the hypothesised model is not supported by the sample data, it is revised in order to improve fit. So, the model is revised by removing the non-significant paths and adding other paths to the model based on the two rules (i) The decision should be based on logic (Arbuckle \& Wothke, 1999; Facteau, Dobbins, Russell, Ladd \& Kudisch 1995) and (ii) it should yield significant results (Mathieu, Tannenbaum \& Salas, 1992). The non-significant path (from tenure with the leader to trust in the leaders) is removed. The other non-significant relationship is retained based on the logic that the tenure with a leader will have an impact on the leader trustworthy behaviour. Further, based on the examination of modification indices, the following three paths are added to the original model, keeping the above two rules (Wothke and Arbuckle, 1995).

(a) Perceived ability to Leader Trustworthy Behaviour: This path is considered because when employees believe that their manger is talented and able, the perceived trustworthy behaviour of the leaders should be higher. 
(b) Perceived interdependence to Leader Trustworthy Behaviour: When the employees feel that the successful performance of the job requires cooperation from their leaders it will have an impact on the Leader Trustworthy Behaviour.

(c) Perceived interdependence to perceived ability: The task interdependence between the leader and the subordinates will create a positive opinion on the Leader's ability.

Table 2. Comparison of structural equation models

\begin{tabular}{lccccccc}
\hline Model & $\chi^{2}$ & $d f$ & $\Delta \chi^{2}$ & RMSEA & CFI & C min/df & p-value \\
\hline 1. Hypothesized Model & 205.538 & 13 & & .215 & .761 & 15.811 & .000 \\
2. Re-Specified Model A & 20.482 & 11 & 185.056 & .052 & .988 & 1.862 & .039 \\
3. Re-Specified Model B & 19.129 & 12 & 1.353 & .043 & .991 & 1.594 & .085 \\
\hline
\end{tabular}

Note: $\mathrm{n}=321$. RMSEA= Root Mean Square Error of Approximation; $\mathrm{CFI}=$ Comparative Fit Indices

The re-specified model A shows a dramatic improvement in fit with a large drop in $\chi^{2}$ from 205.538 in the original model to 20.482 in the re-specified model. All the fit indices (GFI, AGFI, TLI, CFI and NFI) are above the minimum standard of 0.9 and the RMSEA value is 0.52 (refer to table 2) which is less than the prescribed minimum value of 0.8 (Hair et al., 1998; Kline, 2005). As the $\mathrm{p}$ value is still significant $(\mathrm{p}<.05)$, which indicates that the actual and predicted input matrices are statistically different (Hair et al., 1998), the model is considered to be lacking adequate fit.

Table 3. Significance of the model parameters

\begin{tabular}{cccccccc}
\hline Exogenous & Endogenous & \multicolumn{2}{c}{ Hypothesized Model } & \multicolumn{2}{c}{ Re-Specified Model A } & \multicolumn{2}{c}{ Re-Specified Model B } \\
\cline { 3 - 8 } Construct & Construct & Beta & CR & Beta & CR & Beta & CR \\
\hline Tenure $\rightarrow$ & Ability & 0.242 & $3.17^{* *}$ & 0.192 & $2.81^{* *}$ & 0.197 & $2.95^{* *}$ \\
Tenure $\rightarrow$ & PI & 0.115 & $2.07^{*}$ & 0.115 & $2.07^{*}$ & 0.115 & $2.07^{*}$ \\
Tenure $\rightarrow$ & LTB & 0.069 & 1.25 & -0.094 & $-1.93^{*}$ & -0.099 & $-2.11^{*}$ \\
Tenure $\rightarrow$ & BLTS & 0.134 & $2.66^{* *}$ & 0.118 & $2.55^{*}$ & 0.120 & $2.57^{*}$ \\
Tenure $\rightarrow$ & Trust & -0.052 & -1.92 & $($ Parameter Dropped) & & \\
LTB $\rightarrow$ & BLTS & 0.387 & $8.12^{* * *}$ & 0.289 & $4.30^{* * *}$ & 0.295 & $4.41^{* * *}$ \\
LTB $\rightarrow$ & Trust & 0.144 & $3.07^{* *}$ & 0.089 & 1.54 & (Parameter Dropped) \\
Ability $\rightarrow$ & BLTS & 0.269 & $3.42^{* * *}$ & 0.312 & $3.06^{* *}$ & 0.297 & $3.07^{* *}$ \\
Ability $\rightarrow$ & Trust & 0.245 & $3.31^{* * *}$ & 0.249 & $2.85^{* *}$ & 0.306 & $3.88^{* * *}$ \\
PI $\rightarrow$ & BLTS & 0.158 & $3.39^{* * *}$ & 0.119 & $2.37^{*}$ & 0.128 & $2.60^{* *}$ \\
PI $\rightarrow$ & Trust & 0.187 & $4.41^{* * *}$ & 0.149 & $3.41^{* * *}$ & 0.146 & $3.40^{* * *}$ \\
BLTS $\rightarrow$ & Trust & 0.445 & $8.80^{* * * *}$ & 0.423 & $8.39^{* * *}$ & 0.441 & $8.82^{* * *}$ \\
Ability $\rightarrow$ & LTB & (Addition of three more & 0.706 & $4.74^{* * *}$ & 0.699 & $5.17^{* * *}$ \\
PI $\rightarrow$ & Ability & parameters in Model & 0.395 & $4.14^{* * *}$ & 0.380 & $4.34^{* * *}$ \\
PI $\rightarrow$ & LTB & \multicolumn{7}{c}{ A) } & -0.032 & -0.62 & (Parameter Dropped) \\
\hline
\end{tabular}

Note: $\mathrm{n}=321$; Tenure $=$ Tenure with the leader; LTB=Leader Trustworthy Behavior; Ability=Perceived Ability; $\mathrm{PI}=$ Perceived Interdependence; BLTS $=$ Belief that leader trusts subordinates; Trust=Trust in Leaders; ${ }^{*} \mathrm{p}<.05$, $* * \mathrm{p}<.01, * * * \mathrm{p}<.001$ 
As the re-specified model 'A' lacked model fit, the two non significant paths in the model are dropped and a new re-specified model ' $\mathrm{B}$ ' is constructed. Here, the two paths from perceived interdependence to Leader Trustworthy Behaviour and the LTB to the "trust in leader" are dropped as they are not significant (refer to Table 3). The re-specified model ' $\mathrm{B}$ ' as displayed in figure 3 demonstrated a good model fit to the sample data with statistically significant path co-efficients ( $>$ > .05) and further decrease in the $\chi^{2}$ value (Hair et al., 1998). All the fit indices as seen in the table 3 shows a good model fit (GFI, AGFI, TLI, CFI and NFI with values above 0.9) and RMSEA value less than 0.5 (Hair et al., 198, Kline, 2005). Also all the relationships between the variables are proved to be significant (refer to Table 3).

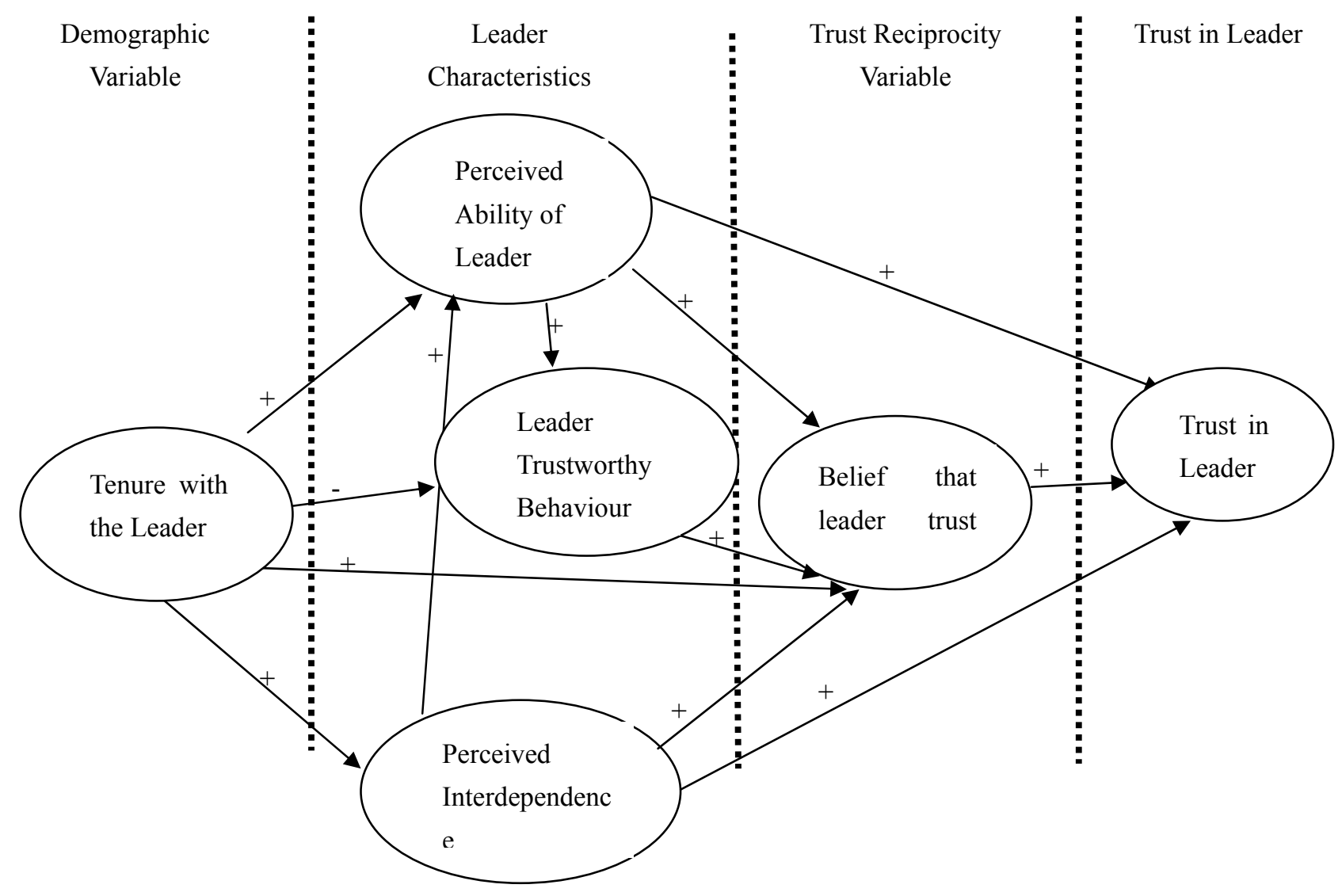

Figure 3. Re-Specified model B

\section{Discussion and Theoretical Implications}

The final structural model clearly identifies the direct and indirect relationships between the leader characteristics and leadership trust formation. Moreover, the relevance of the trust reciprocity variable as an antecedent to the leadership trust formation is empirically established through this study.

It is evident from the study that the tenure of work relationship between the leaders and subordinates will not directly influence the subordinate's trust in leaders (refer to Figure 3). Therefore $H 1$ is not supported. Dirks and Ferrin (2002) also reported a similar lack of relationship between work tenure and trust formation. On the contrary, Lewicki and Bunker (1996) reinforce that the trust in leaders will develop over a course of time. This study through its structural model reveals that the tenure of the work relationship cannot be a direct cause of subordinate's trust in leaders. But, tenure of work strongly influences the leader characteristics, namely, perceived interdependence of work $(\beta=0.115, \mathrm{p}<.05)$, perceived ability of leaders $(\beta=0.197, \mathrm{p}<.01)$, leader trustworthy behaviour $(\beta=-0.099, \mathrm{p}<.05)$ and the trust reciprocity variable "belief that the leader trusts the subordinates" $(\beta=0.120, p<.05)$. These leader characteristics and trust reciprocity in turn influence the leadership trust formation, thereby validating their mediating role in the indirect relationship between work tenure and leadership trust. 
The final structural model (refer to Figure 3 ) clearly validates the hypothesis that the leader characteristics and attributes, namely the task interdependence $(\beta=0.146, p<.001)$ and perceived ability of the leaders $(\beta=0.306$, $\mathrm{p}<.001)$ have a direct impact on the subordinate's trust. Therefore the hypotheses $H 2 a$ and $H 2 b$ are supported. But the Leader Trustworthy Behaviour (LTB) has no direct effect on the subordinate's trust. So, $H 2 c$ is not supported. This is a significant finding revealed though this study. On the contrary, Cardona and Elola (2003) reported that the LTB is having a significant impact on the subordinate's trust levels. But this structural model clearly exemplifies that a leader's trustworthy behaviour cannot directly influence trust formation among subordinates. The leader trustworthy behaviour has an indirect effect on the subordinate's trust, which is strongly mediated by the trust reciprocity variable.

The relevance of the trust reciprocity variable in leadership trust formation is strongly established through the structural model. Therefore, $H 3$ is supported. Amongst all the relationships in the model (as evident in Table 3) the trust reciprocity has a significant impact on leadership trust $(\beta=0.441, p<.001)$. This emphasizes that the subordinate's trust in the leaders is primarily dependent upon the ability and characteristics of the leaders in creating an impression among their subordinates that they believe in them. Therefore, leadership trust is mostly reciprocal and available on a quid pro quo basis from the subordinates. Boyett (2006) opines that trust formation among subordinates is totally a "Give and Take" game and is purely reciprocal upon its initiation from the leader. The finding from this study further validates the reciprocity of trust as identified in the previous studies (Dirks \& Ferrin 2002; Konovsky \& Pugh 1994; Organ, 1990).

\section{Managerial Implications}

The evidence from this study suggests that a manager cannot be able to build trust among subordinates solely through developing a longer working relationship. But such work tenure can indirectly increase the levels of managerial trust by influencing the employee's perception that their work is interdependent with their manager's work and their manager is more competent. Therefore, it is no guarantee that a manager who works for a longer tenure with the subordinates can necessarily build trust in them directly. But, such tenure can build the perceived competence and interdependence of the manager by the subordinates, which in turn can mediate the trust formation between them.

Further evidence from this study establishes that a manager can instill trust among the subordinates by displaying task-based ability and by establishing the interdependent nature of the tasks between them. But, interestingly, trustworthy behaviours from a manager like consistent behaviour, sharing, delegation, open communication and concern cannot guarantee a direct resultant trust formation in subordinates. Such trustworthy behaviour should induce the subordinates to believe that the manager trusts them. This resultant reciprocal belief can substantially influence trust formation among subordinates. Therefore, the manager should initially make their subordinates believe that he/she trusts them through his/her ability, task interdependence and trustworthy actions, which in turn will lead to reciprocal trust formation among the subordinates.

\section{Limitations and Future Directions}

Though earlier researchers used structural equation models to establish causality, it needs to be interpreted with a greater degree of caution. Mere model fit may not establish causality among variables (Pearl, 2011). Therefore, model testing using experimental methods without giving any room for measurement errors and other noise disturbances, is recommended for future studies. The use of single item global scale has drawn much criticism. As the constructs trust reciprocity, leadership trust and task interdependence are measured using single item scales, a more robust multi-item measurement scale is recommended. Here, leadership trust is measured only from the perspective of subordinates and the leader's point of view is not considered, which necessitates a dyadic study of leader-subordinate trust to validate the same findings of this research. Further, external validity of this causal study cannot be safely ascertained given the abovementioned weaknesses in the model (Shadhish, Cook \& Campbell, 2002). Similar studies are required elsewhere to establish the reciprocity of leadership trust development and the role of the antecedent "belief of subordinates that the leader trusts them" in creating reciprocal trust in leaders.

\section{Conclusion}

This study reveals the various antecedents to trust in leaders and emphasizes clearly that the tenure of the work relationship between the leader and subordinates and the leader's trustworthy behaviour will generate a reciprocal trust in them indirectly. For developing trust in their leaders, the subordinates should rather have to believe that the leader trusts them first. The leaders should have to understand this quid pro quo nature of trust creation and exhibit trustful actions and behaviour. These actions of a leader will create a strong belief among the subordinates that the leader trusts them. This in turn will generate trust in leaders. Moreover, the competence 
of the leaders and the perceived interdependence of their jobs will also generate higher trust levels among subordinates towards their leaders. Therefore, the managers have to understand this indirect "Give and Take" nature of trust creation and have to display trustworthy actions and competence over a period of time to increase the trust levels of subordinates.

\section{References}

Arbuckle, J. L., \& Wothke, W. (1999). Amos 4.0 user's guide. Chicago, IL: SPSS.

Boyett, J. (2006). The Science of Leadership: Weapons of Influence-Reciprocity. Retrieved from http://www.jboyett.com/files/Weapons_of_Influence-Reciprocity.pdf

Brockner, J., Siegel, P. A., Daly, J. P., Tyler, T., \& Martin, C. (1997). When trust matters: The moderating effect of outcome favorability. Administrative Science Quarterly, 42, 558-583. http://dx.doi.org/10.2307/2393738

Bromily, P., \& Cummings, L. L. (1996). Transaction cost in organisations with trust. In Bies, R., Lewicki, R., \& Sheppard, B. (Eds.). Research on negotiation in organisations. Greenwich, CT: JA.

Butler, J. K. (1991). Toward understanding and measuring conditions of trust: Evolution of a condition of trust inventory. Journal of Management, 17, 643-663. http://dx.doi.org/10.1177/014920639101700307

Cardona, P., \& Elola, A. (2003). Trust in Management: The Effect of Managerial Trustworthy Behavior and Reciprocity. Working Paper. WP No. 496. IESE Business School, University of Navarra.

Das, T. K., \& Teng, B. (2004). The Risk-Based View of Trust: A Conceptual Framework. Journal of Business and Psychology, 19 (1), 85-116. http://dx.doi.org/10.1023/B:JOBU.0000040274.23551.1b

Dirks, K. T., \& Ferrin, D. L. (2002). Trust in leadership: Meta-analytic findings and implications for research and practice. Journal of Applied Psychology, 87, 611-628. http://dx.doi.org/10.1037/0021-9010.87.4.611

Facteau, J. D., Dobbins, G. H., Russell, J. E. A., Ladd, R. T., \& Kudisch, J. D. (1995). The influence of general perceptions of the training environment on pretraining motivation and perceived training transfer. Journal of Management, 21, 1-25. http://dx.doi.org/10.1177/014920639502100101

Field, A. (2005). Discovering statistics using SPSS (2nd ed.). London: Sage.

Gabarro, J. J. (1978). The development of trust influence and expectations. In Athos, A. G. and J. J. Gabarro (Eds.). Interpersonal behavior: Communication and understanding in relationships: 290-303. Englewood Cliffs, NJ: Prentice-Hall.

Goldsmith, E. B. (1991). Resource Management for individuals and families. New York: West Publishing Company.

Gouldner, A. W. (1960). The norm to reciprocity: A preliminary statement. American Sociology Review, 25, 161-179. http://dx.doi.org/10.2307/2092623

Hair J. F., Anderson, R. E., Tatham, R. L., \& Black, W. C. (1998). Multivariate Data Analysis (5th Edition). Upper Saddle River, NJ: Prentice-Hall, Inc.

Hinkin, T. R. (1995). A review of scale development practices in the study of Organizations. Journal of Management, 21, 967-988. http://dx.doi.org/10.1177/014920639502100509

Hosmer, L. T. (1995). Trust: The connecting link between organizational theory and philosophical ethics. Academy of Management Review, 20, 379-402. http://dx.doi.org/10.5465/AMR.1995.9507312923

Ironson, G. H., Smith, P. C., Brannick, M. T., Gibson, W. M., \& Paul, K. B. (1989). Construction of a job in general scale: A comparison of global, composite and specific measures. Journal of Applied Psychology, 74, 193-200. http://dx.doi.org/10.1037/0021-9010.74.2.193

Josephson, M. (1993). Ethics corps: A training program for teaching ethics in the 90s. Notebook Materials. Marina Del Rey, CA: Josephson Institute for the Advancement of Ethics.

Josephson, M. (1994). Making ethical decision using the six pillars of character. Wes Hanson (Ed.) with Dan McNeill. Marina Del Rey, CA: Josephson Institute for the Advancement of Ethics.

Kee, H. W., \& Knox, R. E. (1970). Conceptual and methodological consideration in the study of trust. Journal of Conflict Resolution, 14, 357-366. http://dx.doi.org/10.1177/002200277001400307

Kline, P. (1999). The handbook of psychological testing (2nd ed). London: Routledge.

Kline, R. (2005). Principles and Practice of Structural Equation Modeling (2 ${ }^{\text {nd }}$ ed.). New York: The Guildford Press

Konovsky, M. A., \& Pugh, S. D. (1994). Citizenship behavior and social exchange. Academy of Management 
Journal, 37, 656-669. http://dx.doi.org/10.2307/256704

Korsgaard, M. A., Brodt, S. E., \& Whitener, E. M. (2002). Trust in the face of conflict: The role of managerial trustworthy behavior and organizational context. Journal of Applied Psychology, 87, 312-319. http://dx.doi.org/10.1037/0021-9010.87.2.312

Kramer, R. M. (1999). Trust and distrust in organisations: Emerging perspectives, enduring questions. Annual Review of Psychology, 50, 569-598. http://dx.doi.org/10.1146/annurev.psych.50.1.569

Kramer, R. M., \& Tyler, T. R. (1996). Wither Trust? In R. M. Kramer and T. R. Tyler (Eds). Trust in organisations: Frontiers of theory and research. Thousand Oaks: Sage, 1-15.

Kramer, R. M., Meyerson, D., \& Weick, K. E. (1996). Swift trust and temporary groups. In R. M. Kramer, and T. R. Tyler, (Eds.). Trust in organisations: Frontiers of theory and research, Thousand Oaks, CA: Sage, 166-195. http://dx.doi.org/10.4135/9781452243610.n1

Lewicki, R. J., \& Bunker, B. B. (1996). Developing and maintaining trust in work relationships. In R.M. Kramer \& T.R. Tyler (Eds.), Trust in organizations: Frontiers of theory and research (pp. 114-139). Thousand Oaks, CA: Sage Publications. http://dx.doi.org/10.4135/9781452243610.n7

Lewicki, R. J., McAllister, D. J., \& Bies, R. J. (1998). Trust and distrust: New relationships and realities. Academy of Management Review, 23, 438-458. http://dx.doi.org/10.5465/AMR.1998.926620

Marquis, J. (2002). Factors influencing employee perceptions of trust within organizations. Professional Doctorate thesis, Murdoch University.

Mathieu, J. E., Tannenbaum, S. I., \& Salas, E. (1992). Influences of individual and situational characteristics on measures of training effectiveness. Academy of Management Journal, 35, 828-847. http://dx.doi.org/10.2307/256317

Mayer, R. C., Davis, J. H., \& Schoorman, F. D. (1995). An integrative model of organizational trust. Academy of Management Review, 20, 709-734. http://dx.doi.org/10.5465/AMR.1995.9508080335

Organ, D. W. (1990). The motivational basis of organizational citizenship behavior. In Staw, B. M. and L. L. Cummings (Eds.), Research in organizational behavior, 12, 43-72. Greenwich, CT: JAI Press.

Pearl, J. (2011). The Causal Foundations of Structural Equation Modeling. In R. H. Hoyle (Ed.). Handbook of Structural Equation Modeling. New York: Guilford Press.

Robinson, S. L. (1996). Trust and breach of psychological contract. Administrative Science Quarterly, 41, 574-599. http://dx.doi.org/10.2307/2393868

Rossiter, J. R. (2008). Content Validity of Measures of Abstract Constructs in Management and Organizational $\begin{array}{llll}\text { Research. British Journal of } & \text { 380-388. }\end{array}$ http://dx.doi.org/10.1111/j.1467-8551.2008.00587.x

Schoorman, F. D., Mayer, R. C., \& Davis, J. H. (1996). Empowerment in veterinary clinics: The role of trust in delegation. Paper presented at the 11th annual meeting of the Society for Industrial and Organizational Psychology. April 26-28th 1996. San Diego, CA.

Shadish, W., Cook, T., \& Campbell, D. (2002). Experimental and quasi-experimental design for generalized causal inference. Houghton-Mifflin, Boston.

Tabachnik, B. G., \& Fidell, L. S. (1996). Using multivariate statistics (3rd ed.). New York: Harper Collins College Publishers.

Von der Heidt, T., \& Scott, D. R. (2007). Partial aggregation for complex structural equation modeling (SEM) and small sample sizes: an illustration using a multi-stakeholder model of cooperative interorganisational relationships (IORs) in product innovation. paper presented at the 21st ANZAM 2007 Conference, Sydney, 4-7 December.

Walker, K., \& Williams, S. (1995). Exploring values and ethics in public issues education. In K. Walker and S. Williams (Eds.). Advanced methodology workshop materials, Kansas State University and Oklahoma State University.

Webber, S. S. (2002). Leadership and trust facilitating cross-functional team success. Journal of Management Development, 21, 201 - 214. http://dx.doi.org/10.1108/02621710210420273

Whitener, E. M., Brodt, S. E., Korsgaard, M. A., \& Werner, J. M. (1998). Managers as initiators of trust: An exchange relationship framework for understanding managerial trustworthy behavior. Academy of Management Review, 23, 513-530. http://dx.doi.org/10.5465/AMR.1998.926624

Wothke, W., \& Arbuckle, J. L. (1995). Graphical model specification with Amos. Eighth Conference on the Scientific Use of Statistical Software, University of Heidelberg, March 28. 